\title{
Measurements of area and the (island) species-area relationship: new directions for an old pattern
}

\author{
Kostas A. Triantis, David Nogués-Bravo, Joaquín Hortal, Paulo A. V. Borges, Henning Adsersen, \\ José María Fernández-Palacios, Miguel B. Araújo and Robert J. Whittaker
}

K. A. Triantis (konstantinos.triantis@ouce.ox.ac.uk) and R. J. Whittaker, Biodiversity Research Group, Oxford Univ. Centre for the Environment, South Parks Road, Oxford, OX1 3QY, UK. - D. Nogués-Bravo and M. B. Araujo, Dept of Biodiversity and Evolutionary Biol., National Museum of Natural Sciences, CSIC, C/Gutierrez Abascal 2, ES-28006, Madrid, Spain. - J. Hortal, NERC Centre for Population Biology, Imperial College London, Silwood Park Campus, Ascot, SL5 7PY, UK. - P. A. V. Borges, Azorean Biodiversity Group, Depto de Ciências Agrárias - CITA-A, Univ. dos Açores, Angra do Heroismo, Terceira, Açores, Terra-Chã, 9700-851. - H. Adsersen, Centre for Macroecology, Dept of Biology, Univ. of Copenhagen, Universitetsparken 15, DK-2100 Copenhagen Ø, Denmark. - J. M. Fernández-Palacios, Depto de Ecología, Facultad de Biologia, Univ. de La Laguna, ES-38206 La Laguna, Tenerife, Islas Canarias, Spain.

\begin{abstract}
The species-area relationship is one of the strongest empirical generalizations in geographical ecology, yet controversy persists about some important questions concerning its causality and application. Here, using more accurate measures of island surface size for five different island systems, we show that increasing the accuracy of the estimation of area has negligible impact on the fit and form of the species-area relationship, even though our analyses included some of the most topographically diverse island groups in the world. In addition, we show that the inclusion of general measurements of environmental heterogeneity (in the form of the so-called choros model), can substantially improve the descriptive power of models of island species number. We suggest that quantification of other variables, apart from area, that are also critical for the establishment of biodiversity and at the same time have high explanatory power (such as island age, distance, productivity, energy, and environmental heterogeneity), is necessary if we are to build up a more predictive science of species richness variation across island systems.
\end{abstract}

The species-area relationship (SAR) is one of the longest and most frequently studied patterns in geographical ecology. Yet there remain some important questions on the nature of this relationship, its causality, quantification and application for both ecologists and conservation biogeographers (Williamson 1981, Lomolino 2001, Scheiner 2003, Whittaker et al. 2005, Whittaker and Fernández-Palacios 2007). The species richness of a region or area is the result of many processes acting across space and time. Thus, the species-area relationship, as with many other patterns arising from complex systems, cannot analytically describe the relative importance of all the processes involved. Instead, we should think of SARs as generalized descriptions that subsume the underlying complexity of ecological systems and highlight the dominant process(es) (Brown 1995, Rosenzweig 1995, O’Hara 2005). Our focus is on the particular case of the island species-area relationship or ISAR (Whittaker and Fernández-Palacios 2007). Within the familiar expression of the ISAR relationship, $S=\mathrm{cA}^{\mathrm{z}}$ (where $S=$ species number for each island, A is area, and $\mathrm{c}$ and $\mathrm{z}$ are constants), $\mathrm{z}$ was interpreted by MacArthur and Wilson (1967) as largely a function of archipelago isolation. However, $\mathrm{z}$ values may have alternative interpretations, for example, related with variation of climatic or biogeographical controls of species pool size, inclusion/exclusion of transient species, and balance in key processes (immigration, extinction, speciation) (Connor and McCoy 1979, Rosenzweig 1995, Willerslev et al. 2002, Drakare et al. 2006, Triantis et al. 2008).

Moreover, the explanatory power of area for species number variations is also variable, with empirical studies demonstrating significant (sometimes dominant) roles for an array of subsidiary variables (e.g. energy, habitat type, disturbance, elevation and island age), suggesting scale- and context- dependency in the species-area relationship (Rosenzweig 1995, Borges and Brown 1999, Whittaker 2000, Whittaker and Fernández-Palacios 2007). One of the most interesting modifications of the traditional approaches to describing ISARs was Wright's (1983) so-called 'species energy theory'. Wright replaced area in the species-area regression with the product of energy and island area. As with area, available energy does not estimate directly the variety of resource types present on an island, but it is likely to be correlated with it (Hawkins et al. 2003, Kalmar and Currie 2006). A similar approach was adopted by Triantis et al. (2003) in the choros model, in which they replaced area with the product of the number of habitat types and island area. The results of both the approaches were 
encouraging, offering, in many cases, improved fits in comparison to the classic species-area regressions and highlighting the need for measures other than area to be incorporated into models describing and predicting island species richness.

One question arising from these alternative models (ISARs, species-energy models, and the choros model) is whether the improvements in model fit arising from the use of more sophisticated measures of island carrying capacity might, in part, reflect the fact that the commonly used planar measures of island area do not adequately estimate the true resource space available to island species (NoguésBravo and Araújo 2006, Fattorini 2007), thus detrimentally affecting the strength of ISARs and the estimates of the parameters of the ISAR models? In general, errors in area estimation based on planar area are likely to be significant only for archipelagos involving substantial variation in topography (Williamson 1988, Willerslev et al. 2002, Fattorini 2007). To investigate this question we use measurements of the total surface area in five different island groups and a wide range of taxa.

Specifically, we address the following questions:

1. Do more accurate measurements of island area increase the fit of the ISARs?

2. How are the two parameters of the classic relationship (c and $z$ ) affected by an increase in the accuracy of measurements of island area? This question has some significance within conservation biogeography, as generalisations concerning the form of ISARs are used in e.g. predicting species losses in fragmented landscapes (e.g. compare Brooks et al. 2002, Grelle et al. 2005, Whittaker et al. 2005, Wilsey et al. 2005, Whittaker and Fernández-Palacios 2007).

3. Which approach leads to greater improvements in model fits: models based on measurements of environmental heterogeneity in combination with traditional planar estimates of area, or models based on more accurate surface area measurements?

\section{Material and methods}

We gathered 19 data sets for nine taxa and five different island groups; four of oceanic and one of continental origin (Table 1). The estimation of the total surface area of each island followed the protocol of Nogués-Bravo and Araújo (2006) and was developed using SAREG 1.2 software (Jenness 2004; see also < http://www.jennessent.com/ arcview/surface_areas.htm $>$ ). Digital elevation models (DEMs) with 90-m pixel resolution (SRTM $90 \mathrm{~m}$ Digital Elevation Data, freely available at <http://srtm.csi.cgiar. $\operatorname{org} />$ ), were used to calculate the three-dimensional surface area of every island. To calculate surface area, the programme starts by converting the raster information of the DEM into a three-dimensional triangulated irregular network structure (TIN), and then calculates the sum of the areas of all the triangles in the TIN. The same software was used to measure planar area of the islands.

We applied $\log S=\log \mathrm{c}+\mathrm{z} \log \mathrm{A}$ (Eq. 1) for both the planar area and the total surface area measures. For the 13 data sets out of the 19 for which measures of habitat diversity were available we applied the choros model, $\log S=\log b+d \log K$ (Eq. 2), where $K$ is the result of the multiplication of the island size (planar area) with the number of habitat types present on the island, and $b$ and $\mathrm{d}$ are constants. The habitat types used originate from: Peck (2001) for the Galápagos group (six habitat types; vegetation zones), Enghoff and Baez (1993) for the Canary Islands (six types; vegetation zones), Borges (unpubl.) for the Azores (three types; vegetation types) and Sfenthourakis (1996) for terrestrial isopods of the Aegean Islands (17 types; several ecological variables). See the respective publications for further descriptions of the habitat classifications. We compare the models using the $\mathrm{R}^{2}$ values as a measure of their goodness-of-fit. As the models have the same number of fitted parameters, the $\mathrm{R}^{2}$ values are directly comparable, without any modification (Triantis et al. 2003, 2005). We also performed a paired t-test to test for the statistical difference between the $\mathrm{z}$ and $\mathrm{c}$ parameters values for Eq. 1 using the two different measures of area. All regressions and the estimation of parameters were carried out using STATISTICA ver. 6.0.

\section{Results}

The minimum, maximum and mean increases in the estimated area (surface area compared to planar) per island group are presented in Table 1 . The analyses of the form and strength of the ISARs using the improved surface measures of island area did not result in significant changes. For each archipelago, the $\mathrm{R}^{2}$ values were almost identical and the same holds for both the $\mathrm{c}$ and the $\mathrm{z}$ parameters of the model, which in each case remained statistically indistinguishable (paired t-test; results not shown) between the models calculated for planar area and those for the adjusted surface area (Table 1). The species-area-habitat relationship (the choros model) exhibited higher descriptive power compared to the classic ISAR (using either planar or surface area estimates) for all the cases studied, although in some the increase of fit was marginal.

\section{Discussion}

Although for certain islands a large increase of the total area was observed (Branco, Cape Verde, 22\%; Corvo, Azores, $16 \%$; Tenerife, Canary Islands, 13\%), in most of the cases the increase in estimated area was relatively modest (Table 1), meaning that ratios of area between the islands of an archipelago can change as the outcome of how area is estimated. However, our results indicate that the calculation of a more accurate measure of island surface size has negligible impact on the fit and form of ISARs, even though our analyses included some of the most topographically diverse oceanic island groups in the world. A similar conclusion was reached by Nogués-Bravo and Araújo (2006), who report no significant output using the same method to improving area estimates in grid-cell based models of species richness across continental Europe. Thus, we conclude that efforts to increase the accuracy of descriptions of the species-area relationship through more 


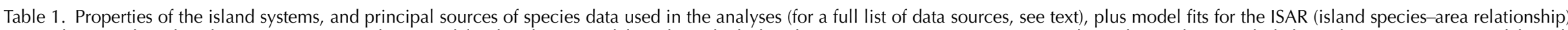

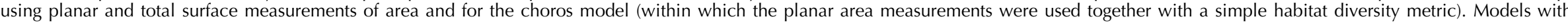
significant fits are indicated with bold face.

\begin{tabular}{|c|c|c|c|c|c|c|c|c|c|c|c|c|c|c|c|c|c|c|c|c|c|}
\hline \multirow[t]{2}{*}{ Island group } & \multirow[t]{2}{*}{ Taxon } & \multirow[t]{2}{*}{ Source } & \multirow{2}{*}{$\begin{array}{l}\text { No. of } \\
\text { islands }\end{array}$} & \multirow{2}{*}{$\begin{array}{l}\text { Elevation } \\
\text { range }\end{array}$} & \multirow{2}{*}{$\begin{array}{l}\text { Min-max } \\
\text { increase of } \\
\text { area (\%) }\end{array}$} & \multirow{2}{*}{$\begin{array}{c}\text { Mean } \\
\text { increase of } \\
\text { area }(\%)\end{array}$} & \multicolumn{5}{|c|}{ ISAR (planar) } & \multicolumn{5}{|c|}{ ISAR (surface) } & \multicolumn{5}{|c|}{ Choros } \\
\hline & & & & & & & z & c & $\mathrm{R}^{2}$ & $\begin{array}{c}\mathrm{F}- \\
\text { values }\end{array}$ & $\begin{array}{c}\mathrm{p}- \\
\text { values }\end{array}$ & z & c & $\mathrm{R}^{2}$ & $\begin{array}{c}\mathrm{F}- \\
\text { values }\end{array}$ & $\begin{array}{c}\mathrm{p}- \\
\text { values }\end{array}$ & z & c & $\mathrm{R}^{2}$ & $\begin{array}{c}\mathrm{F}- \\
\text { values }\end{array}$ & $\begin{array}{c}\mathrm{p}- \\
\text { values }\end{array}$ \\
\hline Canary & arthropods & Izquierdo et al. (2004) & 7 & $670-3711$ & $1.60-13.13$ & 6.65 & - & - & 0.33 & 2.49 & 0.18 & - & - & 0.37 & 2.88 & 0.15 & 0.44 & 63.58 & 0.87 & 34.31 & 0.02 \\
\hline Canary & plants & Izquierdo et al. (2004) & 7 & & & & - & - & 0.31 & 2.25 & 0.19 & - & - & 0.34 & 2.59 & 0.17 & 0.22 & 119.26 & 0.84 & 24.51 & 0.004 \\
\hline Canary & snails & Izquierdo et al. (2004) & 7 & & & & - & - & 0.11 & 0.59 & 0.48 & - & - & 0.13 & 0.73 & 0.43 & 0.36 & 2.25 & 0.58 & 6.86 & 0.047 \\
\hline Canary & birds & Izquierdo et al. (2004) & 7 & & & & - & - & $<0.01$ & $<0.01$ & 0.98 & - & - & 0.001 & 0.007 & 0.94 & - & - & 0.04 & 0.20 & 0.67 \\
\hline Galápagos & $\begin{array}{l}\text { insects } \\
\text { (small orders) }\end{array}$ & Peck (2001) & 13 & & & & 0.31 & 14.20 & 0.66 & 21.5 & $<0.001$ & 0.31 & 13.90 & 0.66 & 21.8 & $<0.001$ & 0.29 & 11.2 & 0.76 & 34.9 & $<0.001$ \\
\hline Galápagos & beetles & Peck (2006) & 13 & 76-1707 & $0.24-7.24$ & 1.85 & 0.24 & 24.50 & 0.76 & 34.4 & $<0.001$ & 0.26 & 24.20 & 0.76 & 34.6 & $<0.001$ & 0.23 & 21.23 & 0.81 & 46.14 & $<0.001$ \\
\hline Galápagos & plants & Lawesson et al. (1987) & 13 & & & & 0.30 & 37.80 & 0.66 & 21.6 & $<0.001$ & 0.30 & 37.00 & 0.67 & 22.0 & $<0.001$ & 0.27 & 29.9 & 0.77 & 37.3 & $<0.001$ \\
\hline Galápagos & birds & Harvey (1994) & 13 & & & & 0.08 & 11.00 & 0.38 & 6.67 & 0.03 & 0.08 & 10.89 & 0.38 & 6.83 & 0.02 & 0.07 & 10.16 & 0.47 & 9.74 & 0.01 \\
\hline Azores & arthropods & Borges et al. (2005) & 9 & & & & 0.47 & 59.99 & 0.84 & 37.43 & $<0.001$ & 0.48 & 56.09 & 0.83 & 33.99 & $<0.001$ & 0.42 & 51.09 & 0.85 & 40.72 & 0.0003 \\
\hline Azores & insects & Borges et al. (2005) & 9 & $718-2351$ & $1.70-16.44$ & 5.75 & 0.46 & 50.10 & 0.86 & 42.54 & $<0.001$ & 0.47 & 46.72 & 0.85 & 39.11 & $<0.001$ & 0.41 & 42.84 & 0.87 & 46.84 & 0.0002 \\
\hline Azores & plants & Silva et al. (2005) & 9 & & & & 0.13 & 47.44 & 0.64 & 12.52 & 0.009 & 0.14 & 46.10 & 0.65 & 12.93 & $<0.001$ & 0.12 & 44.08 & 0.70 & 16.40 & 0.005 \\
\hline Azores & snails & Cunha et al. (2005) & 9 & & & & 0.21 & 14.34 & 0.71 & 17.27 & 0.004 & 0.22 & 13.98 & 0.70 & 15.95 & 0.005 & 0.19 & 13.30 & 0.73 & 18.50 & 0.004 \\
\hline Aegean & isopods & Sfenthourakis (1996) & 25 & 255-1434 & $1.70-16.44$ & 4.66 & 0.25 & 6.58 & 0.78 & 80.67 & $<0.001$ & 0.25 & 6.46 & 0.78 & 79.82 & $<0.001$ & 0.20 & 5.50 & 0.80 & 94.71 & $<0.001$ \\
\hline Aegean & butterflies & Dennis et al. (2000) & 21 & 255-1434 & $1.92-7.59$ & 3.77 & 0.26 & 7.36 & 0.47 & 16.87 & $<0.001$ & 0.26 & 7.36 & 0.48 & 16.86 & $<0.001$ & & & & & \\
\hline Aegean & snails & $\begin{array}{l}\text { Mylonas (1982), } \\
\text { Hausdorf and } \\
\text { Henning (2005) }\end{array}$ & 33 & $112-1297$ & $0.89-12.30$ & 4.40 & 0.31 & 7.02 & 0.74 & 93.96 & $<0.001$ & 0.31 & 6.90 & 0.74 & 94.77 & $<0.001$ & & & & & \\
\hline Cape Verde & birds & Arechavaleta et al. (2005) & 12 & & & & 0.14 & 6.90 & 0.36 & 5.63 & 0.04 & 0.15 & 6.80 & 0.36 & 5.73 & 0.04 & & & & & \\
\hline Cape Verde & arthropods & Arechavaleta et al. (2005) & 12 & $164-2829$ & $0.36-22.03$ & 5.85 & 0.83 & 3.27 & 0.92 & 112.83 & $<0.0001$ & 0.84 & 2.96 & 0.92 & 118.86 & $<0.0001$ & & & & & \\
\hline Cape Verde & insects & Arechavaleta et al. (2005) & 12 & & & & 0.81 & 3.20 & 0.92 & 110.88 & $<0.0001$ & 0.82 & 2.91 & 0.92 & 117.50 & $<0.0001$ & & & & & \\
\hline Cape Verde & plants & Arechavaleta et al. (2005) & 12 & & & & 0.29 & 40.6 & 0.75 & 30.12 & 0.0003 & 0.30 & 38.73 & 0.77 & 33.67 & 0.0002 & & & & & \\
\hline
\end{tabular}


accurate measurements of area will not offer substantial (if any) improvement to the descriptive power of the relationship. As Williamson (1988) noted "...there is little point in being pedantically rigorous in the analysis of species-area plots; the points are fuzzy".

Our analyses also show that the inclusion of a very general measure of environmental heterogeneity (e.g. vegetation types) can substantially improve the descriptive power of models of island species number. The improvement produced by the choros model over a standard ISAR was most pronounced for the Canary Islands, for which the standard ISAR is statistically insignificant for all the taxa considered, whereas the choros model produced a high fit for all the taxa analyzed, with the exception of birds (Table 1). (For a dynamic interpretation of the Canarian richness data set see Whittaker et al. 2007, 2008). The application of the species-area-habitat relationship suffers mainly from the fact that the outcome of the approach is partly sensitive to the decisions regarding the definition of habitats (Triantis et al. 2005) and thus there might be a problem of standardisation of $\mathrm{K}$ (the result of the multiplication of the island's planar area with the numbers of habitat types present on the island; Materials and methods) across studies. Nonetheless, the effectiveness of the choros model is a clear indication that we can develop more powerful models of island species richness by quantifying environmental factors that are truly mechanistically related with ecosystem properties and with species ecological requirements, e.g. island age, isolation, productivity, energy, environmental heterogeneity. In particular, factors like environmental heterogeneity and energy are valuable in describing the available environmental space or the carrying capacity of the island systems (Wright 1983, Currie 1991, Rosenzweig 1995, Kerr and Packer 1997, Borges and Brown 1999, Kerr et al. 2001, Rahbek and Graves 2001, Triantis et al. 2003, Storch et al. 2005, Kalmar and Currie 2006, Whittaker and Fernández-Palacios 2007).

There are difficulties in quantifying the way environment varies, and relating this to the number of species. First, there is a general failure of ecological theory to deal adequately with geographical scale (Whittaker et al. 2001) and therefore the results and conclusion of many ecological studies, in many cases, are biased by scale effects (NoguésBravo et al. 2008). Additionally, the environmental heterogeneity is complex, multifaceted and difficult to quantify from the target organism's perspective in an objective and repeatable fashion. In order to overcome this difficulty, in several cases island altitude has been used as a surrogate of habitat diversity. However, this correlation can greatly vary, depending on the elevational scale and the approach taken for defining habitat types (this study, results not shown). Therefore, caution is needed when elevation is used as a surrogate of habitat diversity.

An additional way of approaching this problem is through Williamson's (1988) concept of environmental heterogeneity having a 'reddened spectrum'. Using the analogy of light which can be split into a spectrum of different colours, similarly ecological phenomena including temporal and spatial series can be resolved into sets of waves of different frequencies or wavelengths (Williamson 1988, p. 107). A reddened spectrum is one in which the lowfrequency events (those happening on longer spatial and temporal scales) explain more of the total variability (of species richness) than high-frequency ones. Williamson adds a second ingredient, by suggesting that the pattern of environmental variation is to some extent fractal, i.e. that as one increases the magnification by which a landscape is studied, more detail becomes apparent in it. The relevance of fractals and the reddened spectrum of environments to a fuller understanding of species-area effects remains to be explored more intensively (Storch et al. 2002, Johnson et al. 2003, Palmer 2007).

On the basis of the simple analyses reported herein, we offer the following pointers. Although area has proved to be the most powerful single variable in explaining variation in island species numbers, it is both an incomplete descriptor and in some ways an incompletely understood descriptor (Whittaker and Fernández-Palacios 2007, Triantis et al. 2008). Whilst increasing area, of itself, means higher population sizes and thus more different species can be accommodated, it is clear that quantification of other factors (e.g. climate, habitat diversity, evolutionary history) that partially co-vary with area, is necessary if we are to develop a more predictive science of species number variation across insular systems. This is evident because even within single archipelagos, increasing the accuracy of the estimation of physical space does not significantly improve model fits, in contrast to models incorporating crude measures of habitat diversity reported herein, and recent global models of variation in island bird species numbers based on climate and area combined (Kalmar and Currie 2006, Whittaker 2006).

Acknowledgements - KAT was supported in this work by a Marie Curie Intra-European Fellowship Program (project 'SPAR', $041095), \mathrm{DNB}$ is supported by the I3P program and JH by the UK Natural Environment Research Council.

\section{References}

Arechavaleta, M. et al. 2005. Lista preliminar de especies silvestres de Cabo Verde (hongos, plantas y animales terrestres). - Consejería de Medio Ambiente e Ordenación Territorial, Gobierno de Canarias.

Borges, P. A. V. and Brown, V. K. 1999. Effect of island geological age on the arthropod species richness of Azorean pastures. - Biol. J. Linn. Soc. 66: 373-410.

Borges, P. A. V. et al. 2005. List of arthropods (Arthropoda). - In: Borges, P. A. V. et al. (eds), A list of the terrestrial fauna (Mollusca and Arthropoda) and flora (Bryophyta, Pteridophyta and Spermatophyta) from the Azores. Direcção Regional de Ambiente and Univ. dos Açores, pp. 163-221.

Brooks, T. M. et al. 2002. Habitat loss and extinction in the hotspots of biodiversity. - Conserv. Biol. 16: 909-923.

Brown, J. H. 1995. Macroecology. - Univ. Chicago Press.

Connor, E. F. and McCoy, E. D. 1979. The statistics and biology of the species-area relationship. - Am. Nat. 113: 791-833.

Cunha, R. et al. 2005. List of molluscs. - In: Borges, P. A. V. et al. (eds), A list of the terrestrial fauna (Mollusca and Arthropoda) and flora (Bryophyta, Pteridophyta and Spermatophyta) from the Azores. Direcção Regional de Ambiente and Univ. dos Açores, pp. 157-161.

Currie, D. 1991. Energy and large-scale patterns of animal- and plant-species richness. - Am. Nat. 137: 27-49. 
Dennis, R. L. H et al. 2000. Contemporary geography dominates butterfly diversity gradients within the Aegean archipelago (Lepidoptera: Papilionoidea, Hesperoidea). - J. Biogeogr. 27: 1365-1383.

Drakare, S. et al. 2006. The imprint of geographical, evolutionary and ecological context on species-area relationships. - Ecol. Lett. 9: 215-227.

Enghoff, H. and Baez, M. 1993. Evolution of distribution and habitat patterns in endemic millipedes of the genus Dolichoiulus (Diplopoda: Julidae) on the Canary Islands, with notes on distribution patterns of other Canarian species swarms. - Biol. J. Linn. Soc. 49: 277-301.

Fattorini, S. 2007. Are planar areas adequate for the species-area relationship? - Ital. J. Zool. 74: 259-264.

Grelle, C. E. V. et al. 2005. Prediction of threatened tetrapods based on the species-area relationship in Atlantic forest, Brazil. - J. Zool. 265: 359-364.

Harvey, L. E. 1994. Spatial patterns of inter-island plant and bird species movements in the Galápagos Islands. - J. R. Soc. N. Z. 24: 45-63.

Hausdorf, B. and Henning, C. 2005. The influence of recent geography, palaeogeography and climate on the composition of the fauna of the central Aegean Islands. - Biol. J. Linn. Soc. 84: 785-795.

Hawkins, B. A et al. 2003. Energy, water, and broad-scale geographic patterns of species richness. - Ecology 84: 105117.

Izquierdo, I. et al. (eds) 2004. Lista de especies silvestres de Canarias (hongos, plantas y animales terrestres) 2004. - Consejería de Política Territorial y Medio Ambiente Gobierno de Canarias.

Jenness, J. S. 2004. Calculating landscape surface area from digital elevation models. - Wildlife Soc. Bull. 32: 829-839.

Johnson, M. P. et al. 2003. The area-independent effects of habitat complexity on biodiversity vary between regions. - Ecol. Lett. 6:126-132.

Kalmar, A. and Currie, D. J. 2006. A global model of island biogeography. - Global Ecol. Biogeogr. 15: 72-81.

Kerr, J. T. and Packer, L. 1997. Habitat heterogeneity as a determinant of mammal species richness in high-energy regions. - Nature 385: 252-254.

Kerr, J. T. et al. 2001. Remotely sensed habitat diversity predicts butterfly species richness and community similarity in Canada. - Proc. Natl Acad. Sci. USA 98: 11365-11370.

Lawesson, J. E. et al. 1987. An updated and annotated checklist of the vascular plants of the Galápagos Islands. - Rep. Bot. Inst., Univ. of Aarhus 16: 1-74.

Lomolino, M. V. 2001. The species-area relationship: new challenges for an old pattern. - Prog. Phys. Geogr. 25: 1-21.

MacArthur, R. H. and Wilson, E. O. 1967. The theory of island biogeography. - Princeton Univ. Press.

Mylonas, M. 1982. The zoogeography and ecology of the terrestrial mollusks of Cyclades. PhD thesis. - Univ. Athens, Greece.

Nogués-Bravo, D. and Araújo, M. B. 2006. Species richness, area and climate correlates. - Global Ecol. Biogeogr. 15: 452-460.

Nogués-Bravo, D. et al. 2008. Scale effects and human impact on the elevational species richness gradients. - Nature 453: 216219.

O'Hara, R. B. 2005. The anarchist's guide to ecological theory. Or, we don't need no stinkin' laws. - Oikos 110: 390-393.

Palmer, M. 2007. Species-area curves and the geometry of nature. - In: Storch, D. et al. (eds), Scaling biodiversity. Cambridge Univ. Press, pp. 15-31.

Peck, S. B. 2001. Smaller orders of insects of the Galápagos Islands, Ecuador: evolution, ecology, and diversity. - NRC Research Press.
Peck, S. B. 2006. The beetles (Insecta: Coleoptera) of the Galápagos Islands, Ecuador; evolution, ecology, and diversity. - NRC Research Press.

Rahbek, C. and Graves, G. R. 2001. Multiscale assessment of patterns of avian species richness. - Proc. Natl Acad. Sci. USA 98: 4534-4539.

Rosenzweig, M. L. 1995. Species diversity in space and time. - Cambridge Univ. Press.

Scheiner, S. M. 2003. Six types of species-area curves. - Global Ecol. Biogeogr. 12: 441-447.

Sfenthourakis, S. 1996. The species-area relationship of terrestrial isopods (Isopoda; Oniscidea) from the Aegean archipelago (Greece): a comparative study. - Global Ecol. Biogeogr. 5: 149-157.

Silva, L. et al. 2005. List of vascular plants (Pteridophyta and Spermatophyta). - In: Borges, P. A. V. et al. (eds), A list of the terrestrial fauna (Mollusca and Arthropoda) and flora (Bryophyta, Pteridophyta and Spermatophyta) from the Azores. Direcção Regional de Ambiente and Univ. dos Açores, pp. 131-155.

Storch, D. et al. 2002. Pink landscapes: 1/f spectra of spatial environmental variability and bird community composition. - Proc. R. Soc Lond. B. 269: 1791-1796.

Storch, D. et al. 2005. The species-area-energy relationship. - Ecol. Lett. 8: 487-492.

Triantis, K. A. et al. 2003. A model for the species-area-habitat relationship. - J. Biogeogr. 30: 19-27.

Triantis, K. A. et al. 2005. Species richness, environmental heterogeneity and area: a case study based on land snails in Skyros archipelago (Aegean Sea, Greece). - J. Biogeogr. 32: 1727-1735.

Triantis, K. A. et al. 2008. Evolutionary species-area curves as revealed by single-island endemics: insights for the interprovincial species-area relationship. - Ecography 31: 401407.

Whittaker, R. J. 2000. Scale, succession and complexity in island biogeography: are we asking the right questions? - Global Ecol. Biogeogr. 9: 75-85.

Whittaker, R. J. 2006. Island species-energy theory. - J. Biogeogr. 33: $11-12$.

Whittaker, R. J. and Fernández-Palacios, J. M. 2007. Island biogeography: ecology, evolution, and conservation (2nd ed.). - Oxford Univ. Press.

Whittaker, R. J. et al. 2001. Scale and species richness: towards a general, hierarchical theory of species diversity. - J. Biogeogr. 28: 453-470.

Whittaker, R. J. et al. 2005. Conservation biogeography: assessment and prospect. - Div. Distr. 11: 3-23.

Whittaker, R. J. et al. 2007. The island immaturity - speciation pulse model of island evolution: an alternative to the "diversity begets diversity" model. - Ecography 30: 321-327.

Whittaker R. J. et al. 2008. A general dynamic theory of oceanic island biogeography. - J. Biogeogr. 35: 977-994.

Willerslev, E. et al. 2002. Number of endemic and native plant species in the Galápagos Archipelago in relation to geographical parameters. - Ecography 25: 109-119.

Williamson, M. H. 1981. Island populations. - Oxford Univ. Press.

Williamson, M. H. 1988. Relationship of species number to area, distance and other variables. - In: Myers, A. A. and Giller, P. S. (eds), Analytical biogeography, an integrated approach to the study of animal and plant distributions. Chapman and Hall, pp. 91-115.

Wilsey, B. J. et al. 2005. Predicting plant extinction based on species-area curves in prairie fragments with high beta richness. - Conserv. Biol. 19: 1835-1841.

Wright, D. H. 1983. Species-energy theory: an extension of species-area theory. - Oikos 41: 496-506. 